\title{
ELISA de bloqueio monoclonal para o diagnóstico sorológico de infecções pelo herpesvírus bovino tipo 1 (BHV-1) ${ }^{1}$
}

\author{
Marjorie F.B. Teixeira ${ }^{2}$, Paulo A. Esteves ${ }^{2}$, Cyntia S. Schmidt ${ }^{2}$, Fernando R. Spilki² \\ Tamir C. Silva ${ }^{2}$, Maria A. Dotta ${ }^{2}$ e Paulo M. Roehe ${ }^{2,3^{\prime \prime}}$
}

\begin{abstract}
Teixeira M.F.B., Esteves, P.A, Schmidt, C.S., Dotta M.A. \& Roehe, P.M. 2001. [A monoclonal blocking ELISA for the serological diagnosis of bovine herpesvirus type 1 (BHV-1) infections] ELISA de bloqueio monoclonal para o diagnóstico sorológico de infeç̧ões pelo herpesvírus bovino tipo 1 (BHV-1). Pesquisa Veterinária Brasileira 21(1):33-37. Centro de Pesquisa Veterinária Desidério Finamor (CPVDF), FEPAGRO, Cx. Postal 2076, Porto Alegre, RS 90001-970, Brazil.

A monoclonal antibody-based blocking enzyme linked immunosorbent assay (ELISA-M) was developed and standardized for the detection of antibodies to infectious bovine rhinotracheitis virus (Bovine Herpesvirus type 1; BHV-1). A total of 266 samples of bovine sera (148 negative and 118 positive) were tested and compared with the results of a standard serum neutralization (SN) test. The ELISA-M was adjusted to $92.37 \%$ sensitivity, $92.56 \%$ especificity, $93.83 \%$ negative predictive value, $90.83 \%$ positive predictive value and to an accuracy of $92.48 \%$, with an agreement index $(\mathrm{k})$ equal to 0.85 . The main advantages presented by the ELISA-M were its practicality and rapidity in performance. This test was shown to be a suitable alternative to SN tests in the detection of BHV-1 antibodies in cattle. However, the ELISA was unable to discriminate between BHV-1 and bovine herpesvirus type 5 (BHV-5) antibodies.
\end{abstract}

INDEX TERMS: Bovine herpesvirus, BHV-1, infectious bovine rhinotracheitis virus, ELISA, monoclonal.

RESUMO-- Um ensaio imunoenzimático do tipo ELISA de bloqueio com anticorpo monoclonal (ELISA-M) foi desenvolvido e padronizado para a detecção de anticorpos contra o vírus da Rinotraqueíte Infecciosa Bovina (Herpesvírus Bovino tipo 1; BHV-1). Foram utilizadas nesta avaliação 266 amostras de soros bovinos, sendo 148 negativos e 118 positivos em testes de soroneutralização (SN). Em comparação com este último, o ELISA-M demonstrou uma sensibilidade de 92,37\%, especificidade de $92,56 \%$, valor preditivo positivo de $90,83 \%$, valor preditivo negativo de $93,83 \%$ e precisão de $92,48 \%$. O índice de concordância $(\mathrm{k})$ entre os testes foi de 0,85 . 0 ELISA-M apresentou como vantagens a rapidez e a praticidade de execução. Com base nestes resultados, o ELISA-M foi con-

\footnotetext{
${ }^{1}$ Aceito para publicação em 7 de março de 2001.

${ }^{2}$ Fundação Estadual de Pesquisa Agropecuária (FEPAGRO), Centro de Pesquisa Veterinária Desidério Finamor (CPVDF), Estrada do Conde 6000, Eldorado do Sul, RS 92990-000.

${ }^{3}$ Laboratório de Virologia, Instituto de Ciências Básicas da Saúde (ICBS)UFRGS.

*Autor correspondente, Caixa Postal 2076, Porto Alegre, RS 90 001-970. Email: proehe@orion.ufrgs.br
}

siderado uma alternativa apropriada para o diagnóstico sorológico de infecções pelo BHV-1. Entretanto, o teste não foi capaz de diferenciar anticorpos induzidos por BHV-1 ou BHV-5.

TERMOS DE INDEXAÇÃO: Herpesvírus bovino tipo 1, rinotraqueíte infecciosa bovina, BHV-1, ELISA monoclonal.

\section{INTRODUÇÃO}

O Herpesvírus Bovino tipo 1 (BHV-1), previamente denominado Vírus da Rinotraqueíte Infecciosa Bovina/Vulvovaginite Pustular Infecciosa, é um membro da família Herpesviridae, subfamília Alfaherpesvirinae (Porterfield 1989). Este vírus é o agente causador de uma série de enfermidades, incluindo a Rinotraqueíte Infecciosa Bovina (IBR), a Vulvovaginite Pustular Infecciosa (IPV), conjuntivites, balanopostites e abortos (Gibbs \& Rweyemamu, 1977).

O BHV-1 tem distribuição ampla, estando presente em quase todos os países de bovinocultura expressiva (Gibbs \& Rweyemamu 1977, Weiblen et al. 1992). Em alguns países da Europa, a infecção já encontra-se em vias de erradicação. Sua importância tem sido tão marcante que a enfermidade será a próxima barreira sanitária ao comércio internacional de bo- 
vinos e correlatos na União Européia (J. T. van Oirschot, comunicação pessoal). No Brasil, grande parte das propriedades apresentam animais sorologicamente positivos para 0 BHV-1 (Ravazzolo et al. 1989, Lovato et al. 1995, Vidor et al. 1995), o que salienta a importância da adoção de medidas com vistas a identificar estes animais, os quais são potenciais disseminadores da infeç̧ão (Fenner et al. 1996).

$\mathrm{O}$ teste sorológico padrão para detecção de anticorpos anti-BHV-1 é a prova de soroneutralização (SN; House \& Baker 1971). A maioria dos laboratórios de diagnóstico virológico veterinário utilizam a $\mathrm{SN}$, isolada ou juntamente com outros ensaios (Ravazzolo et al. 1989, Weiblen et al. 1992, De Stefano et al. 1993, Lovato et al. 1995, Vidor et al. 1995). Entretanto, devido a sua pouca praticidade, alternativas à $\mathrm{SN}$ tem sido buscadas, e uma ampla variedade de testes imunoenzimáticos tem sido empregados no diagnóstico sorológico de infecções pelo BHV-1 (Edwards \& Gitao 1987, Osório et al. 1989, Shen et al. 1991, Kramps et al. 1994, Graham et al. 1997, Van Oirschot et al. 1997, Anônimo 1998). No Brasil, apesar de uma grande população bovina (cerca de 170 milhões de cabeças) ainda existe uma grande carência de testes sorológicos aplicáveis em larga escala, como é o caso dos ensaios do tipo ELISA, forçando a utilização de testes importados. Tendo em vista o preenchimento desta lacuna, no presente estudo descreve-se o desenvolvimento e padronização de um ELISA de bloqueio monoclonal (denominado "ELISA-M"), baseado na competição entre os soros em teste e um anticorpo monoclonal específico anti-BHV-1.

\section{MATERIAL E MÉTODOS}

Células da linhagem MDBK (Madin-Darby Bovine Kidney) foram utilizadas para multiplicação viral, produção de antígenos e realização dos testes de soroneutralização. As mesmas foram cultivadas em Meio Mínimo Essencial de Eagle (MEM, Gibco), suplementado com $5 \%$ de soro fetal bovino (SFB, Nutricel) e $0,001 \%$ de enrofloxacina (Baytril), e multiplicadas seguindo métodos usuais (Paul 1970).

O BHV-1 utilizado para preparação de antígenos para o ELISA e testes de soroneutralização (SN) foi a amostra Los Angeles (LA; Madin et al. 1956), proveniente do Instituto Nacional de Tecnologia Agropecuária (INTA), Castelar-Argentina.

Foram utilizadas 266 amostras de soro bovino provenientes do estoque de soros de nosso laboratório. As amostras foram consideradas positivas ou negativas para anticorpos anti- BHV-1 com base nos resultados obtidos à soroneutralização, como descrito abaixo. Os soros controles positivo e negativo igualmente foram selecionados a partir desse estoque.

Os testes de soroneutralização (SN) foram realizados essencialmente como descrito por House \& Baker (1971), com período de incubação de $1 \mathrm{~h}$ a $37^{\circ} \mathrm{C}$, frente a 100 doses infectantes para $50 \%$ dos cultivos celulares $\left(\right.$ DICC $_{50}$ ) da amostra LA de BHV-1. A leitura das placas foi realizada 48, 72 e 96 horas após o início do teste. Todos os soros foram testadas em quadruplicata. Os títulos dos soros foram determinados pelo método de Reed \& Muench (Lorenz \& Bögel 1973).

Os antígenos $(\mathrm{Ag})$ foram produzidos em garrafas rolantes de $750 \mathrm{ml}$ ou do tipo Povitsky. A infecção das células MDBK foi realizada pela inoculação de $5 \mathrm{ml} /$ garrafa de suspensões virais com um título mínimo de $10^{5}$ doses infectantes para cultivos celulares $50 \%$
DICC $_{50} / \mathrm{ml}$. As mesmas foram coletadas quando o efeito citopático atingiu $90 \%$ da monocamada, porém as células ainda encontravamse aderidas à superfície da garrafa. 0 meio de cultivo foi então removido e o tapete celular tratado com $5 \mathrm{ml}$ de n-octilglicopiranosídeo (OGP) a $0,2 \%$ em solução salina fosfatada (PBS) por $1 \mathrm{~h}$ a $4^{\circ} \mathrm{C}$. Com auxílio de um raspador, as células foram mecanicamente removidas e a suspensão obtida foi centrifugada a 1500x g por 15 minutos. Após, o sobrenadante foi sonicado (Ultrasonics Ltd) em 3 ciclos de 30 segundos a $60 \mathrm{~Hz}$ e novamente centrifugado, aliquotado e estocado a $-70^{\circ} \mathrm{C}$.

O anticorpo monoclonal (AcM) utilizado no ELISA-M, denominado 2G5, foi produzido e caracterizado previamente em nosso laboratório (Silva et al. 1997; Roehe et al. 1997).

A titulação do Ag, AcM, conjugado, soros controles positivo e negativo e determinação dos tempos ótimos de bloqueio foram feitas como descrito previamente (Graham et al. 1998).

Para a execução do ELISA-M, microplacas flexíveis de poliestireno (Hemobag) de 96 orifícios foram sensibilizadas com $200 \mu \mathrm{l}$ /orifício de antígeno $(\mathrm{Ag})$ em uma diluição pré-determinada (1:100 em PBS). As microplacas foram então incubadas por 16 horas a $4^{\circ} \mathrm{C}$ em câmara úmida. No dia seguinte à sensibilização, o antígeno foi retirado e as microplacas foram imediatamente utilizadas no ELISA ou congeladas $a-20^{\circ} \mathrm{C}$ em sacos plásticos até o momento do uso. No momento de execução do teste propriamente dito, foram realizadas três lavagens seguidas com PBS pH 7,2 com 0,05\% de Tween 20 (PBS-T). A seguir, foram adicionados $100 \mu \mathrm{l}$ dos soros em teste, em duplicata, previamente diluidos (conforme diluição previamente determinada: 1:2 em PBS-T). Soros controles positivo e negativo (igualmente diluidos) foram adicionados em quadruplicata. As microplacas foram então incubadas por uma hora a $37^{\circ} \mathrm{C}$ em câmara úmida. As mesmas foram lavadas três vezes com líquido de lavagem e subsequentemente adicionados $100 \mu \mathrm{l} /$ orifício do AcM 2G5 (1:1000 em PBS-T). As microplacas foram novamente incubadas por uma hora a $37^{\circ} \mathrm{C}$ em câmara úmida. Após novo ciclo de três lavagens, foram adicionados $100 \mu \mathrm{l}$ de conjugado peroxidase/ anti-IgG de camundongo (Sigma), previamente diluido (1:1000 em PBS-T ). Após novo período de incubação de 1 hora a $37^{\circ} \mathrm{C} \mathrm{em}$ câmara úmida, as microplacas foram novamente submetidas a um ciclo de três lavagens e, a seguir, adicionados $100 \mu \mathrm{l} /$ orifício de orto-fenilenodiamina (OPD; Sigma) diluída em tampão citratofosfato, contendo $0,003 \%$ de $\mathrm{H}_{2} \mathrm{O}_{2}$. As microplacas foram então incubadas a $37^{\circ} \mathrm{C}$ por cinco minutos, sendo a reação interrrompida pela adição de $50 \mu \mathrm{l}$ /orifício de $\mathrm{H}_{2} \mathrm{SO}_{4} 2 \mathrm{M}$. A leitura dos resultados foi obtida com base na densidade ótica (DO) determinada em espectrofotômetro com comprimento de onda de $492 \mathrm{~nm}$. Após a leitura, foram determinadas as médias das DO de cada soro em teste, dos soros controle positivo e negativo e orifícios nos quais não foram adicionados soros bovinos (controle do AcM). Foi calculada a percentagem de inibição (I\%) de cada soro testado com base na seguinte fórmula:

$$
\mathrm{I} \%=(\text { DO AcM }- \text { DO soro testado }) / \text { DO AcM x 100\%, }
$$

onde "I\%" corresponde à percentagem de inibição e "DO", à densidade ótica. Foram aceitas como válidos todos os testes em que o valor de I\% entre os soros controle positivo e negativo nas placas foi igual ou superior a duas vezes.

\section{Determinação do ponto de corte}

O ponto de corte ("cut off point"), definido como a percentagem de inibição de DO (I\%) a partir da qual os soros são considerados positivos $(>I \%)$ ou negativos $(<\mathrm{I} \%)$, foi calculado com base nas amostras de soro bovino negativas para anticorpos neutralizantes anti BHV-1. 
O cálculo do ponto de corte (Crowther \& Smith,1990) foi feito com base na seguinte fórmula: ponto de corte $=\mu \mathrm{I} \%+1,76 \times \mathrm{s}$, onde " $\mu$ " corresponde à média aritmética, e " $\sigma$ ", ao desvio-padrão. A utilização de 1,76 desvios padrão foi ajustada com vistas a incluir 92,16\% da população de soros verdadeiramente negativos (assim considerados com base nos resultados da $\mathrm{SN}$ ) assumindo uma distribuição normal das densidades óticas nesta população de soros (González, 1974).

A análise estatística dos resultados obtidos foi feita com base no Quadro 1. Foram calculados os índices de sensibilidade, especificidade, valores preditivos e precisão, bem como determinado o índice "k", como descrito previamente (Jekel et al. 1999).

\section{RESULTADOS}

Os testes de soroneutralização evidenciaram 118 soros positivos (títulos iguais ou maiores do que 1:2) e 148 soros considerados negativos (títulos menores do que 1:2).

A média aritmética $(\mu)$ da $\%$ dos soros negativos pela técnica de soroneutralização foi 5,97\%. $O$ desvio padrão $(\sigma)$ calculado foi 20,24. Acrescentando-se à média 1,76 desvios-padrão, correspondentes a $92,16 \%$ da população dentro a curva normal de distribuição (González, 1974) o resultado obtido foi: $I \%=41,60$. Este valor foi estabelecido como o ponto de

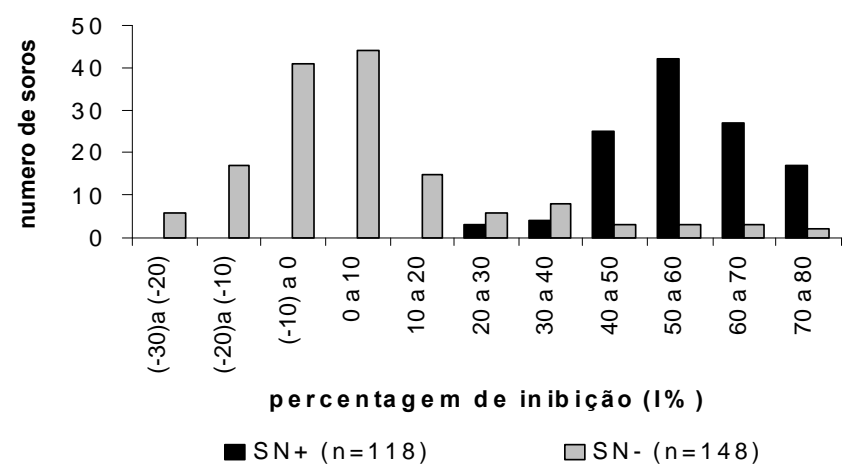

Fig. 1. Distribuição das percentagens de inibição (I\%) no ELISA-M de 118 soros positivos e 148 soros negativos para anticorpos contra o BHV-1 pela prova de soroneutralização $(n=266)$.

Quadro 1. Comparação entre as provas de soroneutralização (SN) e ELISA monoclonal (ELISA-M). $(n=266)$

\begin{tabular}{lccc}
\hline & SN positivo & SN negativo & Total \\
\hline ELISA positivo & 109 & 11 & 120 \\
& (a) & (b) & $(\mathrm{a}+\mathrm{b})$ \\
ELISA negativo & 09 & 137 & 146 \\
& (c) & $(\mathrm{d})$ & $(\mathrm{c}+\mathrm{d})$ \\
Total & 118 & 148 & 266 \\
& $(\mathrm{a}+\mathrm{c})$ & $(\mathrm{b}+\mathrm{d})$ & $(\mathrm{a}+\mathrm{b}+\mathrm{c}+\mathrm{d})$
\end{tabular}

Análise da validade do ELISA-M:

Sensibilidade $(a / a+c) \times 100=109 / 118 \times 100=92,37 \%$

Especificidade $(\mathrm{d} / \mathrm{b}+\mathrm{d}) \times 100=137 / 148 \times 100=92,56 \%$

Valor preditivo negativo $(\mathrm{d} / \mathrm{c}+\mathrm{d}) \times 100=137 / 146 \times 100=93,83 \%$

Valor preditivo positivo $(\mathrm{a} / \mathrm{a}+\mathrm{b}) \mathrm{x} 100=109 / 120 \times 100=90,83 \%$

Precisão $(a+d / a+b+c+d)=246 / 266 \times 100=92,48 \%$ corte do ELISA-M. Assim, amostras com I\% superior a $41,60 \%$ foram consideradas positivas e amostras com $\mathrm{l} \%$ inferior a esse valor foram consideradas negativas (Fig. 1).

Com base nos valores apresentados no Quadro 1 foram calculados os valores de sensibilidade, especificidade, valores preditivos positivo e negativo e precisão obtidos no ELISA$M$ frente à SN. O índice de concordância " $\kappa$ " determinado foi 0,85 .

\section{DISCUSSÃO E CONCLUSÕES}

Foi desenvolvido e padronizado um ELISA de bloqueio (ELISA$\mathrm{M})$, baseado na capacidade de anticorpos anti-BHV-1 presentes em soros bovinos bloquearem a reação do antígeno viral com um anticorpo monoclonal específico contra antígenos do vírus. A padronização do ELISA-M foi feita através da análise comparativa com os resultados obtidos na prova de $\mathrm{SN}$, tomada como prova padrão.

Os testes de $\mathrm{SN}$ foram realizados com incubações da mistura vírus-soro de $1 \mathrm{~h}$ a $37^{\circ} \mathrm{C}$. Segundo alguns autores, este detalhe na metodologia tornaria a $\mathrm{SN}$ menos sensível do que períodos de incubação da mistura soro-vírus de $24 \mathrm{~h}$, ou ainda igualmente menos sensível do que a $\mathrm{SN}$ com a adição de Complemento (Cho \& Bohac, 1985). Por outro lado, o período de incubação mais longo aumenta a probabilidade da ocorrência de resultados falsos positivos (Deregt et al. 1993). Por isso, optou-se por um tempo de incubação de $1 \mathrm{~h}$, sem a adição de Complemento, especialmente para diminuir a possibilidade da ocorrência de falsos positivos à $\mathrm{SN}$.

Um dos problemas freqüentemente encontrados no desenvolvimento de testes do tipo ELISA é a variabilidade entre partidas de antígeno (Bolton 1981). Este tipo de problema não foi observado neste estudo. A metodologia foi estabelescida visando evitar o excesso de etapas à purificação do antígeno, uma vez que a perda de massa antigênica é tanto mais acentuada quanto maior o número de procedimentos utilizados na sua purificação. Assim, para minimizar tais perdas, o número de intervenções necessárias à produção do antígeno foi o menor possível. A sonicação foi acrescentada ao processo com o objetivo de diminuir os acúmulos de massas de antígeno, formados por agregados de restos celulares e proteínas virais. Na opinião dos autores, este procedimento foi, importante para a padronização das suspensões obtidas, o que resultou em antígenos com desempenho bastante uniforme no ELISA-M. Assim, apesar de terem sido preparadas seis partidas de $\mathrm{Ag}$ em diferentes ocasiões, não foi observada grande variabilidade no desempenho das mesmas no ELISA-M.

Diversos tampões tem sido utilizados para a sensibilização de placas com antígenos para testes de ELISA (Bolton 1981, Cho \& Bohac 1985, Kramps et al. 1994). Essencialmente, a escolha do tampão tem sido feita empiricamente. Verificouse aqui que o uso da solução salina fosfatada (PBS) proporcionou uma diferença maior entre as DO de soros positivos e negativos, em comparação com o tampão carbonato/bicarbonato usado em experimentos preliminares (dados não apresentados). Assim, PBS foi adotado como diluente do antígeno, 
o que facilitou a execução da prova, uma vez que o mesmo tampão pode ser utilizado nas etapas subseqüentes do teste.

Em relação ao tempo ideal de parada da prova, observou-se que as diferenças em DO dos soros positivo e negativo mantiveram a mesma proporcionalidade ao longo dos tempos examinados. Assim, optou-se pela parada da reação aos 5 minutos, suficientes para proporcionar uma clara diferença entre DO de soros positivos e negativos, em um menor intervalo de tempo.

Quanto ao suporte para o ELISA-M, as microplacas de poliestireno de fabricação nacional (Hemobag) foram escolhidas essencialmente em função da performance das mesmas, equivalente a dos produtos similares importados (dados não apresentados), além do baixo custo e da facilidade de obtenção. É importante salientar que, independentemente da marca de microplaca utilizada, a cada mudança de lote deve-se proceder à titulação de todos os componentes do ensaio, pois diferenças entre os lotes do produto podem influenciar os resultados dos testes. Da mesma forma, é importante a utilização de controles em cada uma das placas do ensaio, a fim de minimizar o efeito de possíveis variações. Para evitar essa variabilidade, foi introduzido o cálculo da $1 \%$, permitindo ajustes em caso de erro entre microplacas, em uma mesma bateria de testes.

Em relação ao AcM utilizado, o AcM 2G5, produzido no próprio laboratório, permitiu a otimização do ensaio e facilitou o desenvolvimento do mesmo. O AcM 2G5 apresenta uma ampla reatividade frente a amostras de BHV-1 e BHV-5 (Silva et al. 1997). O uso de um AcM como anticorpo de competição, ao invés de um soro policlonal, evitou a ocorrência de reações inespecíficas, comuns quando soros policlonais são empregados.

O ponto de corte ("cut off point") foi ajustado utilizandose média dos resultados negativos mais 1,76 desvios padrão, a fim de adequar o teste à sensibilidade e especificidade proporcionadas pela técnica de SN. Os testes de ELISA são notoriamente reconhecidos por sua elevada sensibilidade (Cho $\&$ Bohac, 1985). Se fosse adotado como ponto de corte o valor correspondente à média acrescida de dois desvios padrão, a sensibilidade (em comparação à $\mathrm{SN}$ ) seria aumentada, porém com prejuízo em relação à sua especificidade.

Um dos problemas de todos os testes de ELISA para BHV-1 disponíveis no mercado é a ausência de informações sobre a capacidade (ou não) de discriminar entre as respostas sorológicas induzidas por BHV-1 ou BHV-5. Embora um estudo visando testar esta hipótese ainda não tenha sido realizado, o mais provável é que os mesmos não permitam a diferenciação entre as respostas induzidas por estes dois tipos de vírus. O ELISA-M aqui apresentado foi desenvolvido e padronizado para uso na detecção de anticorpos contra o BHV-1. Porém, o teste apresentou reatividade cruzada, reconhecendo como positivos animais infectados com BHV-5 (dados não apresentados). Trabalhos encontram-se presentemente em andamento visando o desenvolvimento futuro de um ELISA capaz de distinguir as respostas imunes frente a estes dois tipos de vírus. Com um teste diferencial, espera-se poder avaliar as prevalências relativas de infecções por BHV-1 e BHV-5. Não obstante, o
ELISA-M se constitui em uma excelente alternativa para o diagnóstico sorológico de BHV-1, particularmente por sua praticidade e rapidez de execução. Além disso, embora não tenha sido objetivo do presente trabalho a avaliação comparativa de custos, estima-se que o ELISA-M tenha um custo pelo menos dez vezes inferior ao custo de um teste de SN.

Agradecimentos:- Ao PRONEX, FAPERGS e CNPq pelo suporte financeiro. O presente trabalho foi objeto da dissertação de mestrado de M.F.B. Teixeira junto ao Programa de Pós-Graduação em Ciências Veterinárias (PPG-CIVET), Faculdade de Veterinária, Universidade Federal do Rio Grande do Sul (UFRGS). Durante o curso, a mesma foi bolsista do CNPq. P.M. Roehe é bolsista pesquisador $1 \mathrm{C}$ do CNPq.

\section{EFERÊNCIAS}

Anônimo 1998. ELISA competición fase sólida. Centro Panamericano de Febre Aftosa y Zoonosis, Rio de Janeiro. 15 p.

Bolton C.D. 1981. Evaluation of the critical parameters of a sensitive ELISA test using purified infectious bovine rhinotracheitis virus antigens. Vet. Microbiol. 6: 265-279.

Cho H.J. \& Bohac J.G. 1985. Sensitivity and specificity of an enzyme-linked immunosorbent assay for the detection of infectious bovine rhinotracheitis viral antibody in cattle. Can. J. Comp. Med. 49:189-194.

Crowther J.R. \& Smith H. 1990. ELISA Manual. Institute for Animal Health, Pirbright, Surrey, UK.

De Stefano E., Passos E.C., Mauridis S.C., Kaneto C.N. \& Pituco E.M. 1993. Pesquisa de anticorpos para rinotraqueíte infecciosa bovina/vulvovaginite pustular infecciosa (IBR/IPV) em rebanhos leiteiros da região de Marília-SP. Virológica 93, Porto Alegre, p. 256. (Resumo)

Deregt D., Cho H.J. \& Kozub G.C. 1993. A comparative evaluation of two sensitive serum neutralization tests for bovine herpesvirus-1 antibodies. Can. J. Vet. Res. 57:56-59.

Edwards S. \& Gitao G.C. 1987. Highly sensitive antigen detection procedures for the diagnosis of infectious bovine rhinotracheitis: amplified ELISA and reverse passive haemagglutination. Vet. Microbiol. 13:135-1411.

Fenner F.J., Paul E.P., Gibbs E.J., Murphy F.A, Horzinek M.C. \& Studdert M.J. 1996. Veterinary Virology. 2nd ed. Academic Press, San Diego. 676p.

Gibbs E.P.J. \& Rweyemamu M.M. 1977. Bovine Herpesvirus. Part I. Bovine herpesvirus 1. Vet. Bull. 47:317-343.

González B.G. 1974. .Métodos Estadisticos y Principios de Diseño Experimental. Correlación y Regresión. Universidad Central del Ecuador, Quito, p.93-109.

Graham D.A., Mawhinney K.A., McShane J., Connor T.J., Adair B.M. \& Merza M. 1997. Standardization of enzyme-linked immunosorbent assays (ELISAs) for quantitative estimation of antibodies specific for infectious bovine rhinotracheitis virus, respiratory syncytial virus, parainfluenza- 3 virus, and bovine viral diarrhea virus. J. Vet. Diagn. Invest. 9: 24-31.

Graham D.A., McShane J., Mawhinney K.A., McLaren I.E. Adair B.M. \& Merza M. 1998. Evaluation of a single dilution ELISA system for detection of seroconversion to bovine viral diarrhea virus, bovine respiratory syncytial virus, parainfluenza-3 virus, and infectious bovine rhinotracheitis virus: comparison with testing by virus neutralization and hemagglutination inhibition. J. Vet. Diagn. Invest. 10: 43-48.

House J.A. \& Baker J. A. 1971. Bovine herpesvirus IBR-IPV. The antibody virus neutralization reaction. Cornell Vet. 61:320-335.

Jekel J.F., Elmore J.G. \& Katz D.L. 1999. Epidemiologia, Bioestatística e Medicina Preventiva. Editora Artes Médica Sul, Porto Alegre. 328 p.

Kramps J.A, Magdalena J., Quak J., Weerdmeester K., Kaashoek M.J., MarisVeldhuis M.A., Risjewijk F.A.M., Keil G. \& Van Oirschot J.T. 1994. A simple, specific, and highly sensitive blocking enzyme-linked immunosorbent assay for detection of antibodies to bovine herpesvirus 1 . J. Clin. Microbiol. 9:2175-2181. 
Lorenz R.J. \& Bogel K. 1973. Methods of calculation, p. 321-335. In:Kaplan M.M. \& Koprowsky H. (ed.) Laboratory Tecniques in Rabies. World Health Organization, Geneva.

Lovato L.T., Weiblen R., Tobias F.L. \& Moraes M.P. 1995. Herpesvírus bovino tipo 1 (HBV 1): inquérito soro-epidemiológico em rebanhos leiteiros do Estado do Rio Grande do Sul, Brasil. Ciência Rural, Santa Maria, 25:425-430.

Madin S.H., York C.J. \& McKercher D.G. 1956. Isolation of infectious bovine rhinotracheitis. Virus Science 124: 721-722.

Osório F.A., Srikumaran S., Rhodes M., Christensen D. \& Srikumaran P. 1989. Detection of bovine herpesvirus-1-specific IgM using a capture enzyme immune assay with isotype-specific monoclonal antibodies. Vet. Diagn. Invest. 1:139-145.

Paul J. 1970. Cell and Tissue Cultures. 4th ed. E and S. Livingstone Publisher, London.

Porterfield J.S. 1989. Andrewes' Viruses of Vertebrates. 5th ed. Baillière Tindall, London. 457p.

Ravazzolo A.P., Dal Pizzol M. \& Moojen V. 1989. Evidência da presença de anticorpos para o vírus da rinotraqueíte infecciosa dos bovinos em alguns municípios do Estado do Rio Grande do Sul. Arq. Fac. Vet. UFRGS.17:95-98.
Roehe P.M., Silva T.C., Nardi N.B., Oliveira L.G. \& Rosa J.C.A. 1997. Diferenciação entre os vírus da rinotraqueíte bovina infecciosa (BHV-1) e herpesvírus da encefalite bovina (BHV-5) com anticorpos monoclonais. Pesq. Vet. Bras. 17:41-44.

Shen D.T., Burger D., Li Z. Gorham J.R. 1991. Characterization of monoclonal antibodies to bovine herpesvirus type 1, Los Angeles strain. Vet. Microbiol. 28:25-37.

Silva T.C., Roehe P.M., Nardi N.B. \& Oliveira L.G. 1997. Produção e caracterização de anticorpos monoclonais contra o vírus da rinotraqueíte infecciosa bovina (BHV-1). Arq. Bras. Med. Vet. Zootec. 49(5):513-522.

Van Oirschot J.J.; Kaashoek M.J., Maris-Veldhuis M.A, Weerdmeester K. \& Rijsewijk F.AM. 1997. An enzyme-linked immunosorbent assay to detect antibodies against glycoprotein $\mathrm{gE}$ of bovine herpesvirus 1 allows differentiation between infected and vaccinated cattle. J. Virol. Met. 67:23-24.

Vidor T., Halfen D.C. \& Leite T.E. 1995. Herpesvírus bovino tipo 1 (BHV-1): sorologia de rebanhos com problemas reprodutivos. Ciência Rural, Santa Maria, 25:421-424.

Weiblen R., Kreutz L.C., Canabarro T.F., Schuch L.F. \& Rebelato M.C. 1992. Isolation of bovine herpesvirus 1 from preputial swabs and semen of bull with balanoposthitis. J. Vet. Diagn. Invest. 4:341-343. 